\title{
Complex Computer Applications and Techniques for Solving Problems with the Inherent Errors and Synthesis of Optimal Characteristics of Materials and Design Parameters
}

Sergey A. Nekrasov

South Russian State Polytechnical University 132 Prosvesheniya, Novocherkassk, 346428, Russia

Received 30.04.2015, received in revised form 26.08.2015, accepted 12.09.2015

The article deals with the complex computer applications and techniques for solving problems with the fatal errors and synthesis of optimal characteristics of materials and design parameters. A number of examples of typical problems solved these programs and methods.

Keywords: Applications, methods, inherent errors, synthesis, optimization, characteristics, materials parameters.

DOI: $10.17516 / 1999-494 X-2015-8-7-867-877$.

\section{Комплекс прикладных программ и методов \\ для решения задач с неустранимой погрешностью \\ и синтеза оптимальных характеристик материалов \\ и конструктивных параметров}

С.А. Некрасов

Южно-Российский государственный политехнический университет (НПИ) имени М.И. Платова Россия, 346428, Новочеркасск, ул. Просвещения, 132

В статье рассматривается комплекс прикладных программ и методов для решения задач c неустранимой погрешностью и синтеза оптимальных характеристик материалов $и$ конструктивных параметров. Приводится ряд примеров типичных задач, решаемых этими программами и методами.

Ключевые слова: прикладные программы, методы, неустранимые ошибки, синтез, оптимизация, характеристики, параметры, материалы.

(C) Siberian Federal University. All rights reserved

* Corresponding author E-mail address: Nekrasoff_Novoch@mail.ru 
Parameters and characteristics of mathematical models in practice is often known only approximately. At the same time there is a significant need for consideration of the effect of initial data errors on the solution of the problem. This is due to the requirements of improving the reliability of devices to prevent accidents and disasters.

Another urgent Problem - the synthesis of optimum characteristics of the materials and of the design parameters. One of the difficulties here is the high dimensionality of the relevant Problems.

\section{Classes of Problems}

Problems can be both linear and nonlinear, stationary and dynamic.

Main allowable applications:

- Linear and nonlinear algebraic optimization

- Eigenvalue problem

- Calculation of the electric and electronic circuits

- Electrostatics and electrodynamics

- The theory of heat conduction, including phase transitions

- The theory of elasticity and thermoelasticity

- Hydro and gas dynamics, aerodynamics

- Optimal control problem

- Equations of chemical kinetics

- Kolmogorov equation

- Mechanical dynamics equations

- Problems in the theory of composite and powder materials

- Problems in the Theory of Heat and Mass Transfer

- Virtually any non-standard combination of these models

\section{Additional Features}

1. Sensitivity of the solutions to the problem of change of its coefficients.

2. Optimization of the shape and size of structures and accounting errors of their parameters.

3. Building a robust (simplified) models.

\section{Specific advantages of the method}

Number of the approximately given parameters is unlimited and does not influence the computational cost and accuracy of the method.

In contrast to methods based on statistical modeling or on linearization the solution almost exactly calculated regardless of the magnitude of variation of the parameters and characteristics.

An important advantage of this method is its effectiveness in the case of functional errors that are more difficult to take into account the methods variants, or the method of statistical modeling (error characteristics of materials and design parameters are very often to be seen as functional).

A numerical method, based on which the program is relatively simple, but very effective and versatile (detailed information can be provided for an extra charge).

Standard packages (Pscpice, ELCUT, SAMCEF, etc.) do not provide the user with such capabilities. 


\section{Examples of typical tasks}

\subsection{Problem of linear and non-linear programming with approximate coefficients}

Example: The objective function: $\mathrm{f}(\mathrm{x}, \mathrm{p}) \rightarrow \max \{\mathrm{x} \in \Omega\}$.

Restrictions: $a x=b, a \in A, b \in B ; p \in P$.

Notation: $\mathrm{x}$ - vector of optimization variables, $\Omega$ - area optimization, a - approximation of a given matrix, $\mathrm{b}, \mathrm{p}$ - approximation of a given vector, A - interval matrix, $\mathrm{B}, \mathrm{P}-$ interval vectors.

\subsection{Accounting error characteristics of materials and other parameters of the problem}

Example 1. Calculation of Transient with the error in the initial data. The corresponding Cauchy problem for the system of equations of state nonlinear electric circuit:

$$
\mathrm{dx} / \mathrm{dt}=\mathrm{f}(\mathrm{x}, \mathrm{t}, \mathrm{u}), \mathrm{t} \in\left(0, \mathrm{t}_{\mathrm{F}}\right) ; \mathrm{x}(0)=\mathrm{x}_{0},
$$

where $\mathrm{x}, \mathrm{f}$, and $\mathrm{u}$ - vector function:

$\mathrm{x}=\left(\mathrm{x}_{1}, \ldots, \mathrm{x}_{\mathrm{m}}\right), \mathrm{f}=\left(\mathrm{f}_{1}, \ldots, \mathrm{f}_{\mathrm{m}}\right), \mathrm{u}=\left(\mathrm{u}_{1}, \ldots, \mathrm{u}_{\mathrm{r}}\right), \mathrm{x}_{0}-$ the vector of initial conditions: $\mathrm{x}_{0}=\left(\mathrm{x}_{01}, \ldots, \mathrm{x}_{0 \mathrm{~m}}\right)$, $\mathrm{x}$ - vector of dependent state variables, $\mathrm{u}$ - the vector of parametric and functional errors in describing the accuracy of the job characteristics of the circuit elements: $u \in V=\left\{\left|u_{i}\right| \leq u_{i 0}, i=1, \ldots, r\right\}$.

The error parameter may be a constant $\left(u_{i}=\right.$ const), and functional $u_{i}=u_{i}(t)$.

Results of the solution: interval estimates of the solution $\mathrm{x}\left(\mathrm{t}_{\mathrm{F}}\right)$ or some other specified quality criteria - functional $\mathrm{J}\left(\mathrm{u}, \mathrm{t}_{\mathrm{F}}\right)$ on the set $\mathrm{V}$.

Example 2. The calculation of the potential $\varphi$ and the electric field vector $\mathbf{E}=-\operatorname{grad} \varphi$ :

$$
\operatorname{div}(\varepsilon \operatorname{grad} \varphi)=-\rho, M \in V ; \varphi=\vartheta(M), M \in \Gamma,
$$

where $\mathrm{M}$ - the point of the computational domain $\mathrm{V}$ with coordinates $(\mathrm{x}, \mathrm{y}, \mathrm{z}), \Gamma$ - border area;

$\varepsilon=\varepsilon(\mathrm{M}, \mathrm{E}), \rho=\rho(\mathrm{M}), \vartheta=\vartheta(\mathrm{M})-$ approximation of a given dielectric constant, charge density, the potential on the boundary:

$$
\varepsilon \in\left[\varepsilon_{-}(\mathrm{M}, \mathrm{E}), \varepsilon_{+}(\mathrm{M}, \mathrm{E})\right], \rho \in\left[\rho_{-}(\mathrm{M}), \rho_{+}(\mathrm{M})\right], \vartheta \in\left[\vartheta_{-}(\mathrm{M}), \vartheta_{+}(\mathrm{M})\right] .
$$

Results solutions - the corresponding ranges of values of the potential $\varphi$ or the electric field $\mathbf{E}(\mathrm{M})$ : $\varphi \in\left[\varphi-(\mathrm{M}), \varphi_{+}(\mathrm{M})\right], \mathbf{E} \in\left[\mathbf{E}-(\mathrm{M}), \mathbf{E}_{+}(\mathrm{M})\right], \mathrm{M} \in \mathrm{V}$.

\subsection{Synthesis of optimal characteristics of materials and design parameters}

The selection of suitable material properties, providing maximum values of quality in the field of the given points.

Example. The calculation of the optimum parameters of the problem for the temperature field:

$$
\operatorname{div}(\lambda \operatorname{grad} u)+q=0, M \in V ; u=\varphi, M \in \Gamma ; F(u) \rightarrow \max ,
$$

where $\mathrm{M}-\mathrm{V}$ point computational domain coordinates $(\mathrm{x}, \mathrm{y}, \mathrm{z})$,

$\lambda=\lambda(\mathrm{u}, \mathrm{M}), \mathrm{q}=\mathrm{q}(\mathrm{u}, \mathrm{M}), \varphi=\varphi(\mathrm{M})$ - the desired thermal conductivity, heat distribution and temperature values on the boundary, which may belong to a set of values:

$$
\lambda \in\left[\lambda_{-}(\mathrm{u}, \mathrm{M}), \lambda_{+}(\mathrm{u}, \mathrm{M})\right], \mathrm{q} \in\left[\mathrm{q}(\mathrm{u}, \mathrm{M}), \mathrm{q}_{+}(\mathrm{u}, \mathrm{M})\right], \varphi \in\left[\varphi_{-}(\mathrm{M}), \varphi_{+}(\mathrm{M})\right] .
$$


$\mathrm{F}(\mathrm{u})$ - a functional qualities: it may be, for example, the temperature at point responsible $\mathrm{u}\left(\mathrm{M}^{*}\right)$, maximum, minimum or average value of the temperature: $\max (\min , \operatorname{mid}) \mathrm{u}(\mathrm{M}), \mathrm{M} \in \mathrm{V}$; integral criterion $\int \mathrm{k}(\mathrm{u}(\mathrm{M}), \mathrm{M}) \mathrm{dV}_{\mathrm{M}}$, etc.

Results solutions - the optimal values of the material characteristics and other parameters of the problem: $\lambda^{\text {opt }}(\mathrm{u}, \mathrm{M}), \mathrm{q}^{\mathrm{opt}}(\mathrm{M}), \varphi^{\mathrm{opt}}(\mathrm{M})$.

\section{Calculation examples}

\subsection{Calculating the electrical rectifier circuit}

with approximately specified characteristics and parameters

Uncertainties circuit parameters $-1 \%$ for CVC diode $-10 \%$.

Fig. 2 shows that in the typical area of inrush current in a nonlinear inductance the difference of solutions is significantly due to the higher sensitivity of the solution to the values of the circuit parameters. For these reasons, the traditional solution obtained by the average values of the parameters is not practically acceptable.

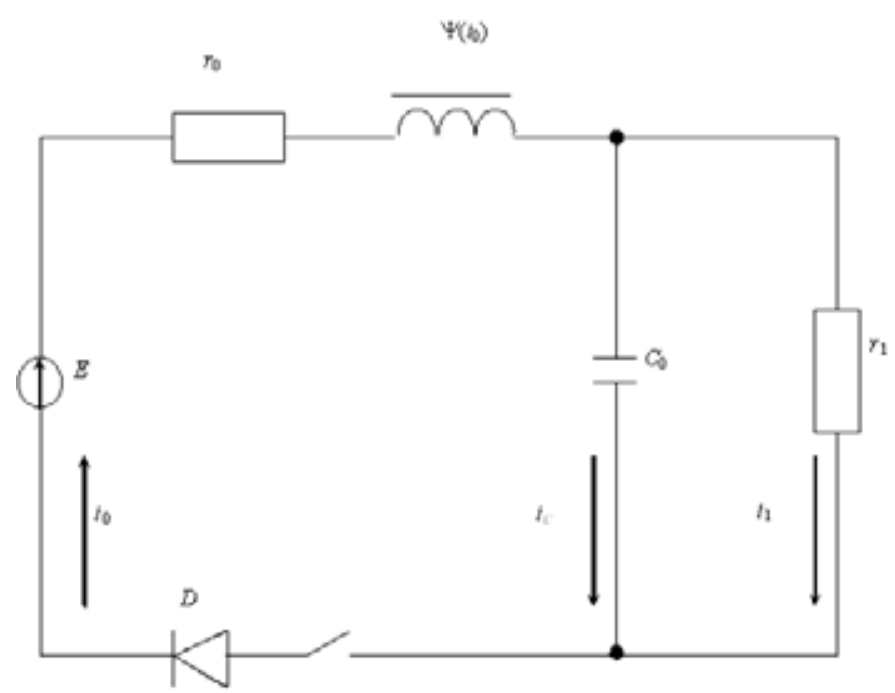

Fig.1. The electrical circuit
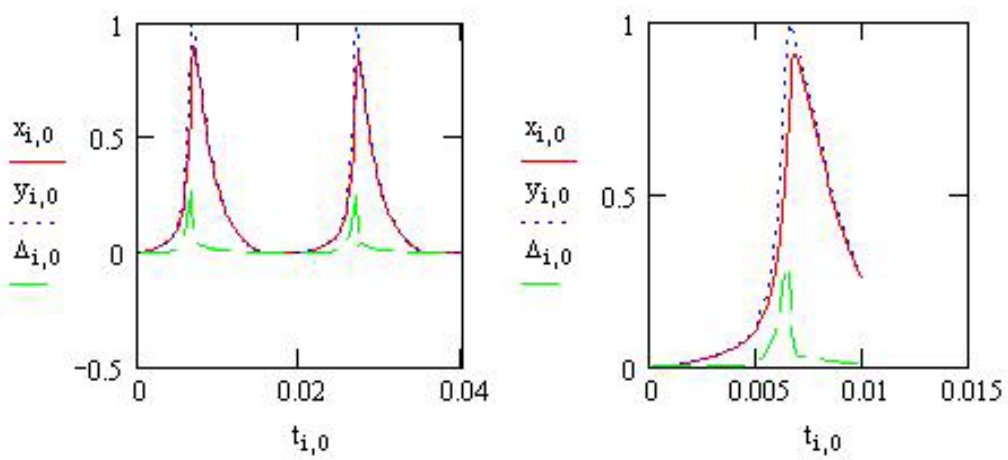

Fig. 2. Graphs of the upper and lower bounds of the current and the difference between them 


\subsection{The calculation of the temperature interval in glower}

Examines steel thread with length of $10 \mathrm{~cm}$ and a diameter of $0.1 \mathrm{~mm}$ was heated with $20 \mathrm{~mA}$ current magnitude. At the ends of the filament temperature is kept constant. The average values of the thermal conductivity of $90 \mathrm{~W} /(\mathrm{mK})$, conductivity $10^{5} \mathrm{~S} / \mathrm{m}$, the error for these parameters is considered to be $5 \%$.

The problem was solved by the method of finite differences in integration step of $1 \mathrm{~cm}$ and accuracy of the solution of finite-difference equations of about $0.5 \%$. Graphs corresponding estimates for the top and bottom temperature distribution shown in Fig. 3.

\subsection{The calculation of the temperature interval in stream conductive liquids}

Examines the electroconductive liquid flow in a channel with a rectangular cross-section (length $50 \mathrm{~cm}$, dimensions sides cross section $10 \mathrm{~cm}$, the flow rate of $0.1 \mathrm{~cm} / \mathrm{s}$ ).

Heating of the liquid is carried out by the current flowing along the canal and created by the voltage difference at the ends of the channel value of $1 \mathrm{~V}$.

At the ends of the channel maintains a constant temperature (inlet - the melting point, the output at $500 \mathrm{~K}$ more). On the walls of the channel temperature varies linearly with the preservation of continuity of the temperature field.

The average values of the thermal conductivity of the fluid $-58 \mathrm{~W} /(\mathrm{mK})$, the electrical conductivity of $5,8 \cdot 10^{6} \mathrm{~S} / \mathrm{m}$ (parameters of molten steel), errors of these parameters are, respectively, $10 \%$ and $5 \%$ is important to note that these errors are, generally speaking, functional, as appropriate values can vary within this range at random points in the fluid volume (this observation is relevant to all the above examples).

Formulation of the boundary value problem has the form:

$$
\operatorname{div}(\lambda \operatorname{grad} u)-v \partial u / \partial x+q=0, M \in V ; u=\varphi, M \in \Gamma,
$$

where $\mathrm{v}-$ velocity of fluid flow, $\mathrm{q}-$ heat density: $\mathrm{q}=\mathrm{J}^{2} / \gamma, \mathrm{J}-$ the current density, $\gamma$ - conductivity.

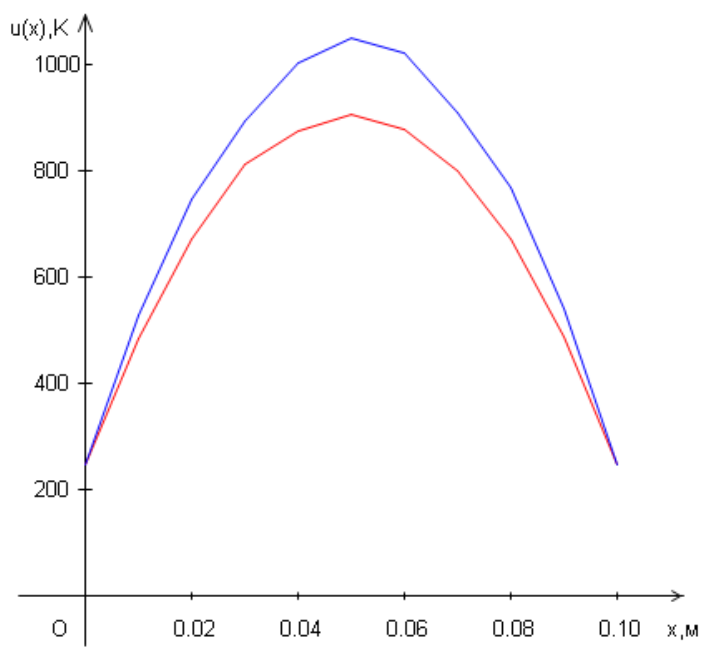

Fig. 3. Graphs upper and lower bounds of temperature 
The corresponding two-dimensional problem is solved by the method of finite differences in the integration step of $2.5 \mathrm{~cm}$ as the abscissa (along the channel), and the ordinate axis (perpendicular to the longitudinal axis of symmetry of the channel) and the accuracy of the solution of finite difference equations about $5 \%$. Graphs corresponding estimates for the top and bottom of the temperature distribution along the longitudinal axis of the channel shown in Fig. 4 and 5 (with origin on the vertical axis the temperature is done as on the left side of the channel).

\subsection{Calculation of rods deflection}

The differential equation for the transverse deformation of the rod $\mathrm{u}(\mathrm{x})$ :

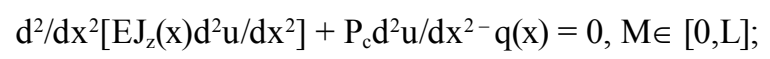

wherein $E J_{z}(x)$ - the stiffness of the rod, $P_{c}$ - force compressing rod with its ends, $q(x)$ - specific shear force distributed over the length of the rod.

The boundary conditions depend on the method of fixing the ends of the rod. In the case of fixing the hinge they have the form: $\mathrm{u}=0, \mathrm{~d}^{2} \mathrm{u} / \mathrm{dx}^{2}=0$ for $\mathrm{x}=0$ and $\mathrm{x}=\mathrm{L}$.

Fig. 6 shows the results of the boundary problem solutions under the following conditions: the material of the rod - wood, density of $500 \mathrm{~kg} / \mathrm{m}^{3}$, the modulus of elasticity $\mathrm{E}=10^{4} \mathrm{MPa}$, and the
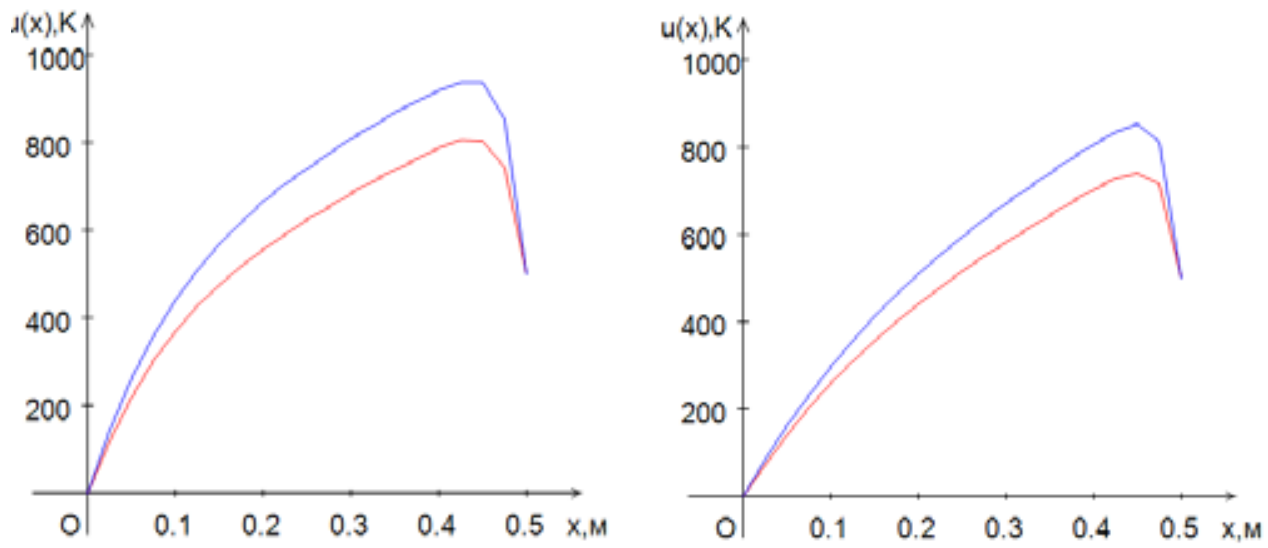

Fig. 4. The graphs of upper and lower bounds of the temperature increments (flow rate $0,1 \mathrm{~cm} / \mathrm{s}$, and $0,2 \mathrm{~cm} / \mathrm{s}$ )
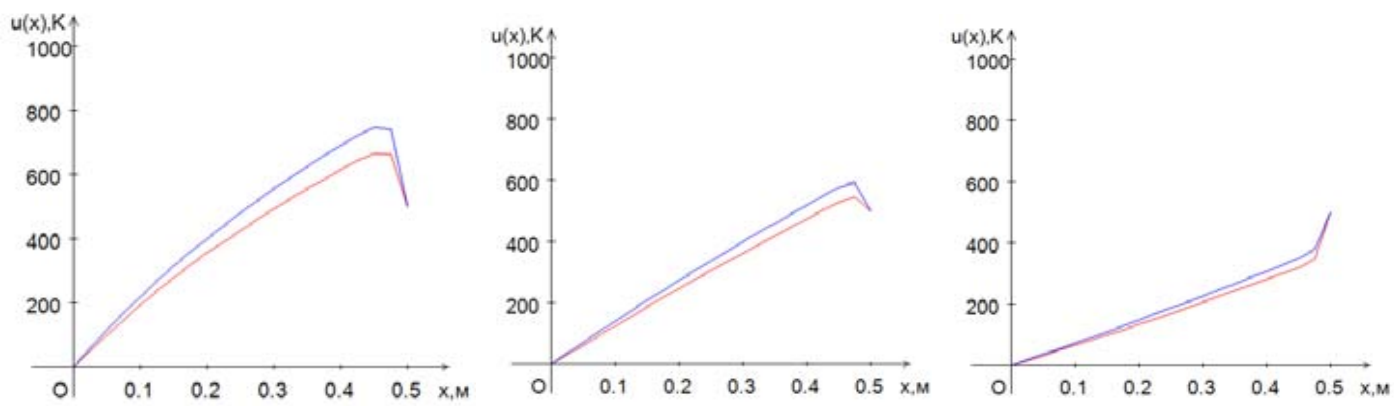

Fig. 5. The graphs temperature ranges for the values of the flow velocity of $0.3 \mathrm{~cm} / \mathrm{s}, 0.5 \mathrm{~cm} / \mathrm{s}$ and $1 \mathrm{~cm} / \mathrm{s}$ 


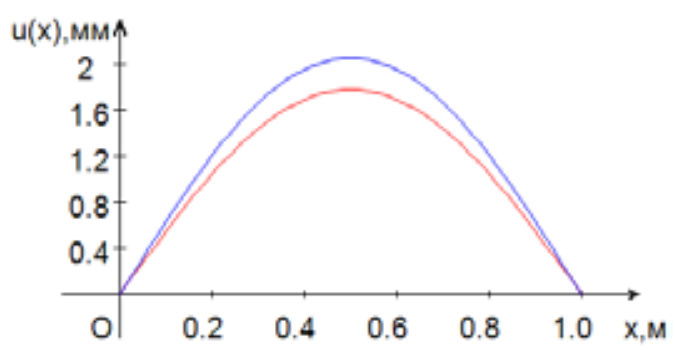

Fig. 6. Upper and lower estimates of the horizontal shear deformations of the rod by its own weight

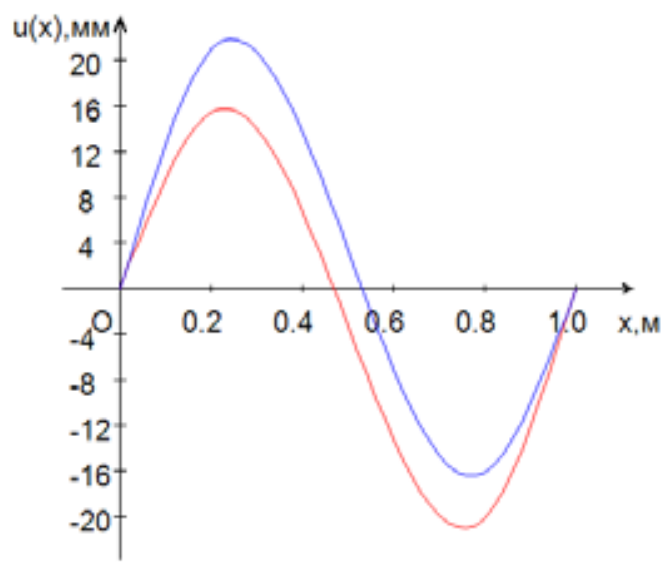

Fig. 7. The upper and lower estimates of the magnitude of the transverse deformation of the vertical rod under the action of opposing concentrated forces

cross section of the rod has a circular shape with a diameter $\mathrm{d}=1 \mathrm{~cm}$, thus the geometric moment of inertia is $\mathrm{J}_{\mathrm{z}}=\pi \mathrm{d}^{4} / 64$, rod length $\mathrm{L}=1 \mathrm{~m}$. The error of the mass of the rod is equal to $2 \%$, and the error value of the rigidity of the rod $-5 \%$ (it is important to consider that this error, generally speaking, functional as stiffness can fluctuate within certain limits on the length of the rod). The rod bends under its own weight $(0.38 \mathrm{~N})$. The compressive strength is 4 times the weight of the rod. Integration step $-2 \mathrm{~cm}$.

Fig. 7 shows the results of similar solutions of the boundary problem with the following conditions: the material of the rod - wood with the same density of $500 \mathrm{~kg} / \mathrm{m}^{3}$ and the modulus of elasticity $\mathrm{E}=10^{4} \mathrm{MPa}$, and the cross section of the rod has a circular shape with a diameter $\mathrm{d}=2$ $\mathrm{mm}$, the rod length $\mathrm{L}=1 \mathrm{~m}$. The error value is equal $2 \%$ to mass of the rod, and the error value of the rigidity of the rod $-5 \%$. The rod bends under the force concentrated at two points on the axis of the rod at the distance of $20 \mathrm{~cm}$ from its ends. The forces are equal in magnitude (equal to twice the weight of the rod) and are oppositely directed. Compressive force equal to the weight of the rod $(0.015 \mathrm{~N})$. Integration step $-2 \mathrm{~cm}$.

These solutions show that the error of material characteristics and design parameters may significantly influence the amount of deformation the structural elements (rods, beams, etc.) and should be considered in critical cases. 
Problems of the strength and reliability calculation for different designs can be solved by a similar method to account for any variations of parameters and characteristics.

\subsection{Calculation of deflection of plates}

The differential equation for the transverse deformations wafer $\mathrm{w}(\mathrm{x}, \mathrm{y})$ :

$$
\partial^{4} w / \partial x^{4}+2 \partial^{4} w / \partial x^{2} \partial y^{2}+\partial^{4} w / \partial x^{4}=q(x, y) / D, M \in S,
$$

where $\mathrm{D}$ - cylinder stiffness of the plate: $\mathrm{D}=\mathrm{E} \delta^{3} /\left[12\left(1-\mu^{2}\right)\right], \mathrm{E}$ - elastic modulus of the material, $\delta$ - plate thickness, $\mu$ - Poisson's ratio, $q(x, y)$ - specific transverse force, acting on the plate; $\mathrm{x}$ - the abscissa, $y$ - the ordinate of a point in the Cartesian coordinate system on the surface of the plate; applicate $\mathrm{Oz}$ axis is perpendicular to the plate.

The boundary conditions depend on the method of fixing the edges of the plate. For fixing the fixed deflection function $\mathrm{w}(\mathrm{x}, \mathrm{y})$ and its normal derivative at the edges of the plate are equal to zero: $\mathrm{w}=0, \partial \mathrm{w} / \partial \mathrm{n}=0$, when $\mathrm{M} \in \mathrm{G}$.

Mechanical stresses (normal $\sigma_{x}, \sigma_{y}$ and tangents $\tau=\tau_{x y}=\tau_{y x}$ ) are expressed in terms of the deflection:

$$
\begin{aligned}
& \sigma_{\mathrm{x}}=-12 \delta^{-3} \mathrm{D}\left(\mathrm{w}_{\mathrm{xx}}+\mu \mathrm{w}_{\mathrm{yy}}\right) \mathrm{z}, \sigma_{\mathrm{y}}=-12 \delta^{-3} \mathrm{D}\left(\mathrm{w}_{\mathrm{yy}}+\mu \mathrm{w}_{\mathrm{xx}}\right) \mathrm{z}, \\
& \tau=-12 \delta^{-3} \mathrm{D}(1-\mu) \mathrm{w}_{\mathrm{xy}} \mathrm{z}, \mathrm{z} \in[-\delta / 2, \delta / 2] .
\end{aligned}
$$

The value of $\sigma_{z}$ considered to be zero.

Consider a particular account when the shear force is random:

$$
\mathrm{q}(\mathrm{x}, \mathrm{y})=\mathrm{P} \times \exp \left[-\left(\mathrm{x}-\mathrm{x}_{\mathrm{c}}\right)^{2} / 0.25-\left(\mathrm{y}-\mathrm{y}_{\mathrm{c}}\right)^{2} / 0.25\right]
$$

where $\mathrm{x}_{\mathrm{c}}$ and $\mathrm{y}_{\mathrm{c}}$ are uniformly distributed in the area $\mathrm{S}, \mathrm{P}=100 \mathrm{~Pa}$.

The plate has a square shape. Side length of $1 \mathrm{~m}$, a thickness of $0.001 \mathrm{~m}$. The plate material aluminum:

$$
\mathrm{E}=7 \times 10^{10} \mathrm{~Pa}, \mu=0.34 .
$$

In the graphs in Fig. $8-13$ shows the results of solving the problem of the finite difference method. The integration step for each coordinate of about $3 \mathrm{sm}$.

The method allowed the author to find the statistical characteristics of the solution is 100 times more economical than the conventional Monte Carlo method.

The graphs show that the solution of the Monte Carlo method has a significant error and clearly skewed. Acceptable precision is achieved only when the number of iterations of about 1,000.

Understood that the solving 1000 times two dimensional, especially three-dimensional boundary value problem is relatively expensive.

Using one of the failure criteria, e.g., $|\tau|<\tau_{\max }$, the calculation can be carried structural strength. Tensile strength 50-60 MPa aluminum achieved at a force 20 times larger than in the example. The sample mean and sample standard for stress makes it relatively easy to estimate the probability of structural failure.

As noted above, the methods and programs of the author's for considered problems for much more efficient than methods of linearization of the small parameter and Monte Carlo. 

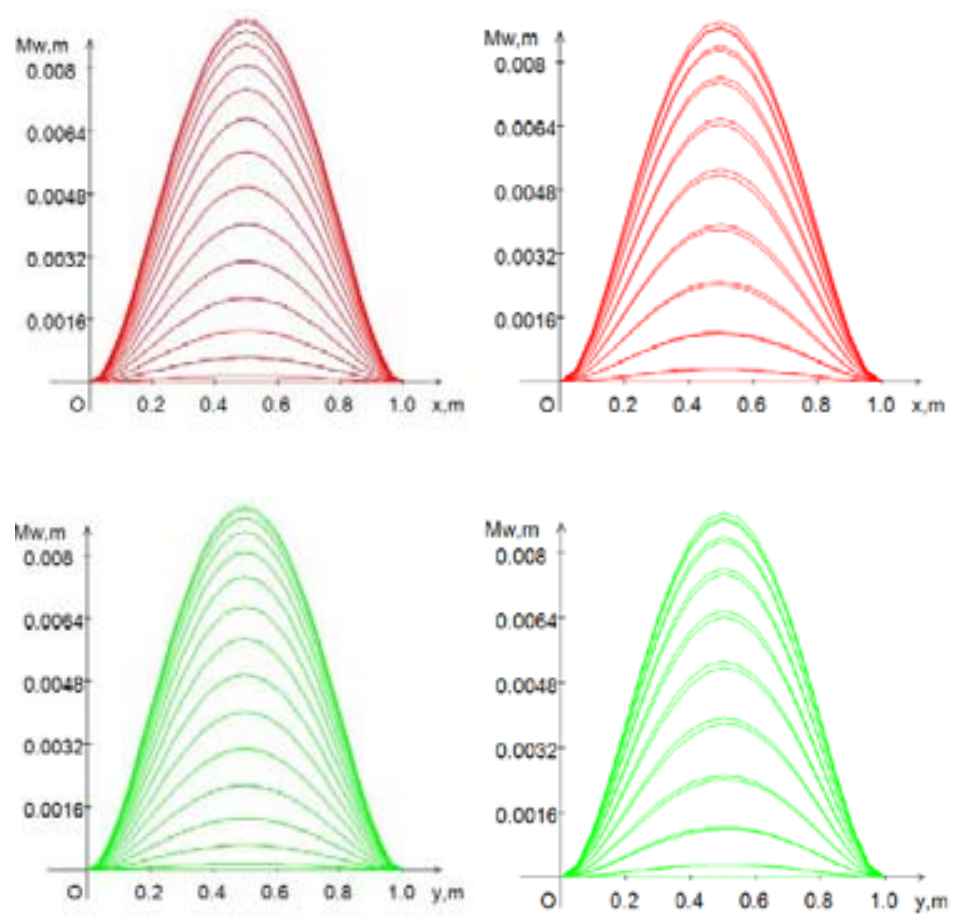

Fig. 8. The sample mean of the deflection of the plates (right decision Monte Carlo at 100 iterations)
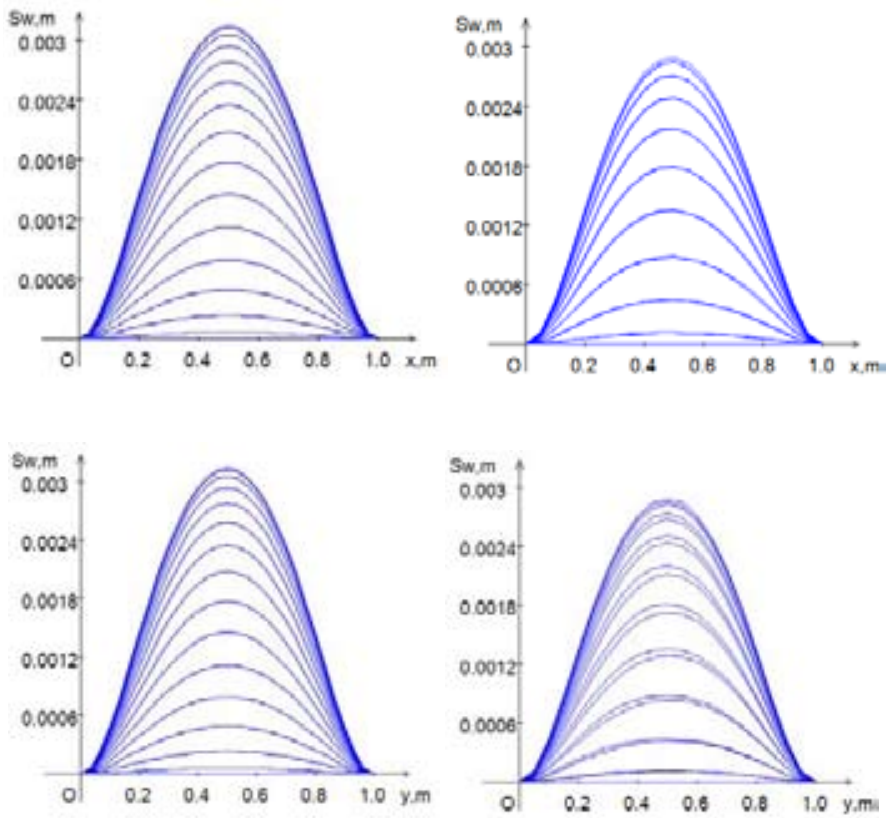

Fig. 9. Selective distribution standard of the deflection of the plates (right decision Monte Carlo at 100 iterations) 

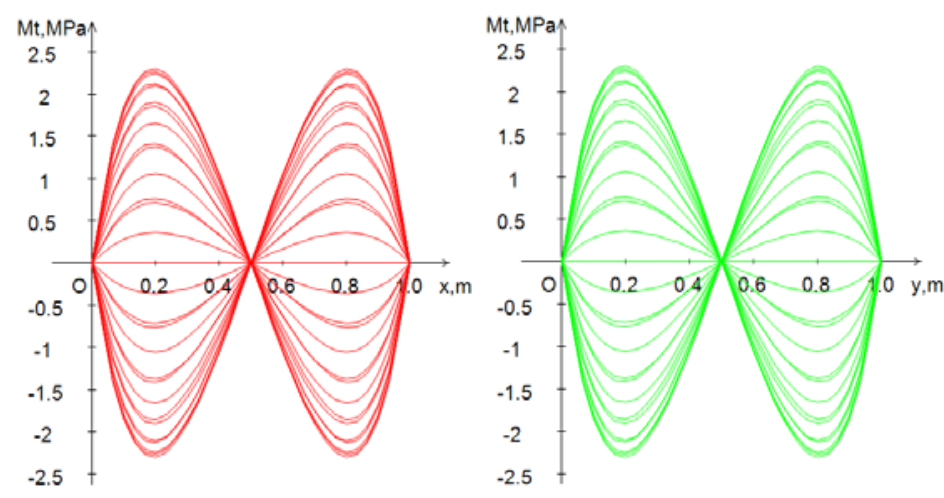

Fig. 10. Sample mean of the shear stresses
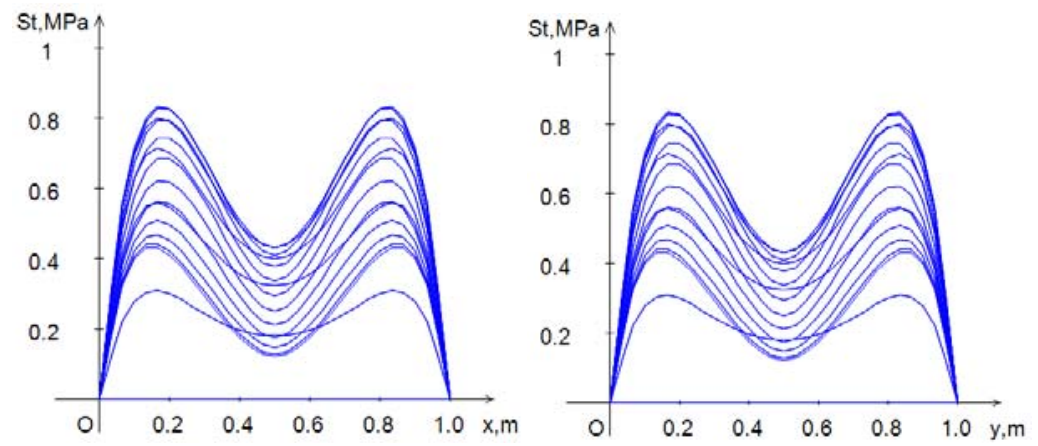

Fig. 11. Selective standard of the shear stresses
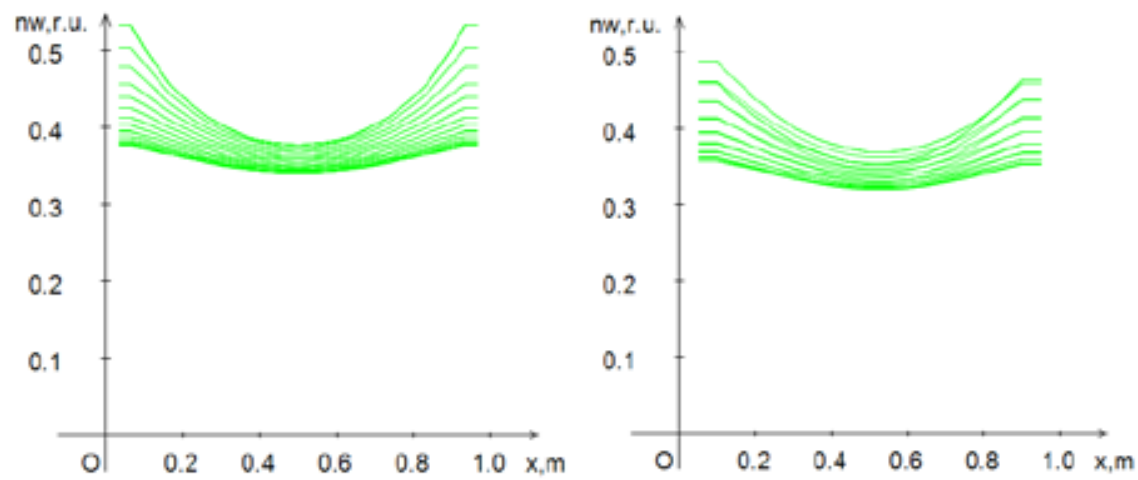

Fig. 12. The coefficient of variation of the deflection of the plates (right decision Monte Carlo at 100 iterations) 


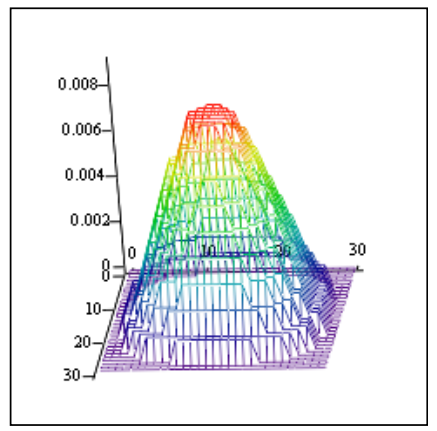

$\mathrm{Mw}$

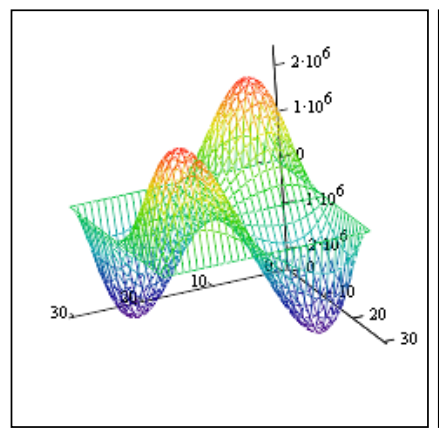

Mt

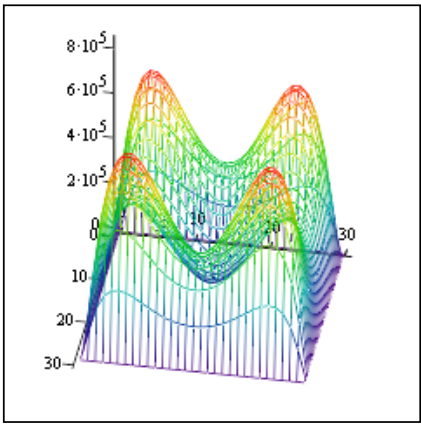

st

Fig. 13. Three-dimensional graphs of the statistical characteristics of deflections and shear stresses

\section{References}

[1] Nekrasov S.A. Thesis for Doctor of Technical Sciences. Specialty «Theoretical Electrical Engineering». Novocherkassk, 2002. http://www.dissercat.com/content/intervalnye-i-dvustoronniemetody-dlya-rascheta-s-garantirovannoi-tochnostyu-elektricheskikh

[2] Nekrasov S.A. et al. // Mat. modelirovanie. 1994. V.6. № 9. P. 33-40.

[3] Nekrasov S.A. // Electricity. 2001. № 8. http://vlib.ustuarchive.urfu.ru/electr/nom08_01.html [4] Nekrasov S.A. // Differential Equation. 2003. V. 39. № 7. 